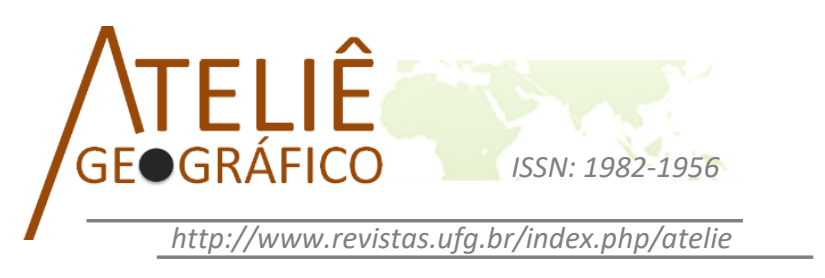

\title{
Presença-ausência da água na cidade: narrações hidropoéticas no habitar urbano contemporâneo
}

\author{
Presencia-ausencia del agua en la ciudad: narraciones \\ hidropoéticas en el habitar urbano contemporáneo

\section{Presence-absence of the water in the city: hydropoetic narratives in the contemporary urban dwelling}

\author{
Diana Alexandra Bernal Arias \\ Universidade Estadual de Campinas \\ dianabernal@ige.unicamp.br \\ Eduardo Marandola Junior \\ Universidade Estadual de Campinas \\ eduardo.marandola@fca.unicamp.br
}

\begin{abstract}
Resumo
Quais são as narrações, as hidropoéticas da água no habitar urbano contemporâneo? Quais marcas e traços podemos encontrar em nossas cidades quando falamos da água? Estas são as perguntas guias deste trabalho. A partir delas percorreremos um caminho entre as presenças e ausências da água. Para compreender as formas e lugares da água na atualidade, refletimos sobre a crescente dessacralização da água fundada na separação homem-terra, para assim desvelar, através da experiência, o papel existencial da água. Para isto, nos localizamos em um conjunto de bairros perto do rio Piçarrão no centro sul da cidade de Campinas, São Paulo, Brasil. Neste lugar, as poéticas da água ou hidropoéticas vão nos narrar o próprio sentido de nosso habitar hídrico, a partir das experiências dos moradores com base em quatro imagens hidropoéticas: 1) Fundar um lugar, 2) Rio próximo e distante ao mesmo tempo, 3) Momentos vulneráveis e 4) Chuva.
\end{abstract}

Palavras-chave: Narrações da água, habitar, fenomenologia geográfica, geografia humanista.

\section{Resumen}

¿Cuáles son las narraciones, las hidropoéticas del agua en el habitar urbano contemporáneo? ¿Qué marcas, huellas podemos encontrar en nuestras ciudades cuando hablamos del agua? Estas son las preguntas guías de este trabajo, a partir de 
ellas recorreremos un camino entre las presencias y ausencias del agua. Para comprender las formas y lugares del agua en la actualidad, reflexionaremos sobre la creciente desacralización del agua fundada en la separación hombre-tierra, para así revelar, a través de la experiencia el papel existencial del agua. Para esto, nos situamos en un conjunto de barrios cerca del río Piçarrão en el centro sur de la ciudad de Campinas, São Paulo, Brasil. En este lugar las poéticas del agua o hidropoéticas nos narraran el propio sentido de nuestro habitar hídrico, desde las experiencias de los moradores a partir de cuatro imágenes hidropoéticas: 1) Fundar un lugar, 2) Río cercano y distante al mismo tiempo, 3) Momentos vulnerables y 4) Lluvia.

Palabras clave: Narraciones del agua, habitar, fenomenología geográfica, geografía humanista

\begin{abstract}
What are the water's hydropoetic narratives in the contemporary urban dwelling? What marks, footprints can we find in our cities when we talk about water? These are the guiding questions of this work, from them we will walk a path between presences and absences of water. To understand the forms and places of water today, we will reflect on the growing desacralization of water based on the man-earth separation, to reveal, through the experience, the existential role of the water. For this, we are located in a set of neighborhoods near the Piçarrão river in the south center of the city of Campinas, Sao Paulo, Brazil. In this place the poetics of water or hydropoetics will tell us the meaningitself of our water dwelling, from the experiences of the dwellers, form four hydropoetic images: 1) To found a place, 2) River near and distant at the same time, 3) Vulnerable moments and 4) Rain.
\end{abstract}

Keywords: narratives of water, inhabit, geographic phenomenology, humanist geography.

\title{
Introdução: a água entre presenças e ausências
}

$\mathrm{Na}$ atualidade, quando falamos da água, temos a impressão de que estamos nos referindo mais a um conceito abstrato e distante de nossa realidade do que a uma água palpável e seus múltiplos sentidos em nossa existência. Apresenta-se uma ambiguidade; a água que está tão presente em nossa vida, que está onipresente no diário viver, também parece estar sumamente ausente em nossa existência ao se converter em mais um recurso, sem lhe dar a importância merecida em nossas experiências. Este duplo e amplo sentido que circunscreve a água, entre ausências e presenças, marca o começo para um questionamento sobre o lugar da água no habitar urbano contemporâneo, o qual nos remete ao papel espacial existencial da água.

A questão sobre o lugar da água no habitar urbano contemporâneo e seu duplo sentido aparece encaminhada pela pergunta que se fez o filósofo Jeff Malpas sobre as formas da água em seu texto "The forms of water: in the land and in the soul" (MALPAS, 2006). Malpas, começa sua procura dando à água este duplo sentido, tanto de presença como de ausência e não só um (ou presença ou ausência), como tendemos a pensar em primeira instância. No entanto, ao falamos apenas de uma forma, esta tende a remeter ao que é visível, enquanto o invisível parece ser carente de sentido. Assim, as 
ausências, por serem "invisíveis", passam desapercebidas sem que compreendamos que também fazem parte da forma e seu sentido, portanto, ausências e presenças estão ligadas uma à outra.

Nesta relação entre presenças e ausências, aquilo visível e invisível, dotado ou não de sentido e a maneira como aparece a água, definem a forma que damos a ela; ou como a compreendemos e as relações que com ela, a partir dela e com ela construímos. Isto é, seu espaço existencial, o lugar da água. Pensaríamos que um conceito abstrato de água, por ser um pouco mais delineado e com limites mais concisos, seria mais apreensível para nosso entendimento do que o conceito de uma água mutável, autopoiésica, simbiótica, do contato. Na realidade, esta água com forma idealizada está tão distante de nossas vivências que sua compreensão parece mais uma imposição à água; a simples vista é mais caótica e muito mais próxima a nós por falar a partir de nossas experiências e não de modelos abstratos.

A água, mais que um recurso, expressa a própria grafia da terra, naquilo que o filósofo José Luís Pardo denomina como geografia (PARDO, 1991). Esta geografia se refere, da mesma maneira que o propõe o geógrafo Éric Dardel, a uma língua ou grafia da terra, o que implica uma hermenêutica viva das formas terrestres que entrelaçam homem-terra em uma ligação de cumplicidade: a geograficidade (DARDEL, 2011).

A água, como elemento terrestre, compõe o próprio sentido de nosso habitar, à maneira de Heidegger (2012a), como constituinte de nossa própria forma de existência. Portanto, este habitar é também um habitar hídrico no sentido existencial.

Esta compreensão nos permite pensar a água como poética (criação e vida) e como constituinte de nosso próprio habitar. Permite também que realizemos um movimento de escuta às narrações, ou seja, à língua que permeia toda a vida. Esta escuta promove uma narrativa que permite que as poéticas da água, ou hidropoéticas (BERNAL, 2015), nos aproximem de seu sentido existencial como condição humana terrestre, para retornar ao sentido proposto por Hannah Arendt (2005).

Contudo, nosso habitar contemporâneo, especialmente nas áreas urbanas, é de crise e de produção sistemática de ausência dos sentidos da água. Há uma crise civilizatória, urbana e ambiental para ser enfrentada, que justifica e ao mesmo tempo desafia a procura pelos sentidos hidropoéticos da água. Devido a isto, neste artigo propomos construir um caminho de pensamento para confrontar este desafio, procurando o lugar da água no habitar urbano contemporâneo, entre ausências e presenças, através das hidropoéticas.

As hidropoéticas são as narrações conjuntas da relação água-lugar-experiências. Sua compreensão expressa a essência do habitar ligado à água; Como são infinitas as maneiras de ser e estar da água, do mesmo modo são as hidropoéticas que se podem criar. As marcas, traços que podemos encontrar da água em nosso habitar, são desveladas com os lugares, sendo a partir deles que conseguimos criar movimentos de 
resistência frente ao ritmo do pensar racionalizador que busca impor uma única direção aos sentidos da água.

Desta forma, compreendemos algumas ausências e presenças da água, a partir das narrações hidropoéticas que foram possíveis interpretar em uma investigação realizada entre 2013 e 2014, em bairros densamente urbanizados na cidade de Campinas (São Paulo, Brasil) (BERNAL, 2015).

\section{A água na crise do habitar}

Na história das diferentes culturas do mundo é possível vislumbrar como a água tem tido muitos significados que mudaram, que aparecem e desaparecem segundo as caraterísticas particulares de cada lugar, ou melhor, com elas. Saide Kahtouni mostra isso detalhadamente para o caso de São Paulo, a partir do manejo e das tecnologias utilizadas na fundação da cidade que criaram a civilização e a urbanidade em São Paulo (KAHTOUNI, 2004).

A água possui mais de uma significação e estas podem chegar a ser divergentes (MARTOS-NÚÑEZ; MARTOS-GARCÍA, 2015). Isto não quer dizer que elas se anulem, ao menos não a princípio. Melhor ainda, podem enriquecer nossa compreensão da água. O problema repousa em um sentido que se impõe aos outros.

O ato de dar uma única forma à água, ou atribuir um só sentido, especialmente um sentido que seja excludente, repercute em certo direcionamento na maneira de agir, gerenciar, planificar. Ou seja, o ato de descartar significados e dar um único lugar à água nos limita nas maneiras como habitamos, como organizamos, compreendemos e vivemos nosso mundo.

Em nosso habitar urbano contemporâneo, com grandes traços de um pensamento ocidental, atravessamos uma crise da água. São alguns dos sentidos da água que têm predominado, oferecendo-lhe um único lugar entre tantos possíveis. O saber científico moderno, racional, funcional e utilitarista tem prevalecido e tem se imposto sobre as outras possíveis formas de compreensão da água. Os saberes populares são relegados e desvalorizados, tomados como falácias carentes de conhecimento válido, interpretados como mitos em um sentido pejorativo (PIÑEYRO, 2006), da mesma maneira que tudo aquilo que não tem sido considerado útil a partir de um papel econômico se estima como de menor valia e importância. São vários os autores (BRUNI, 1994; PIÑEYRO, 2006; GRATÃO, 2008; ILLICH apud MARTOS-NÚÑEZ; MARTOS-GARCÍA, 2015; NOGUERA; BERNAL, 2015) que apontam esta transformação da água; a partir de sua dessacralização, objetivação e consequente transformação em mercadoria e elemento. Para Bruni (1994), por exemplo, no final do século XVIII a água se torna $\mathrm{H}_{2} \mathrm{O}$, corpo incolor, inodoro e líquido, sendo um corpo mais entre outros. Para Illich (apud MARTOS-NÚÑEZ; MARTOS-GARCÍA, 2015), no 
século XIX surge o imaginário do $\mathrm{H}_{2} \mathrm{O}$, no qual podemos evidenciar a síntese metafórica do capitalismo, onde a água é percebida como mercadoria e produto tecnológico.

A crise da água é uma crise mais profunda, é uma crise do habitar e de nossa própria existência. Crise ambiental, civilizatória de nossa cultura que surge da separação do homem com a terra, da perda da terra natal (ÁNGEL MAYA, 2002; NOGUERA, 2004; NOGUERA; BERNAL, 2015). A relação do homem com a água é mais complexa do que pensamos, seu papel existencial é vasto e "muitos são os caminhos da água na vida humana" (GRATÃO, 2008, p.211). Segundo Bachelard (1989), é um tipo de destino. Sabemos das funções multifacetadas que ocupa em nossas vidas, como seus sentidos estão no econômico, no político, no social, no físico, no biológico, entre outros. É um elemento integrante que nos fala sobre as necessidades humanas e não humanas, inclusive vai além das necessidades, faz parte dos diferentes planos de nossa vida; "mais do que produzir meras satisfações, a água costuma ser responsável por um amálgama de experiências sensoriais que envolvem os cinco sentidos" (CASTELO, 1996, p.28).

Bruni (1994) ressaltou como é necessária para todas as tarefas domésticas e orgânicas e Porto-Gonçalves (2006) nos mostrou como o ciclo da água não é externo à sociedade, fazendo parte de suas diferentes dimensões sociais: o privado, o íntimo e o público se dão graças à água. As civilizações e a cultura se fundam em e com ela; qualquer tipo de assentamento humano estão, em seus fundamentos, ligados com a abundância de água. Em especial os rios permitiram o nascimento de grandes civilizações: no Egito, o Nilo; na Mesopotâmia, o Tigre e o Eufrates; na China, o rio Amarelo e o Huang He; na África, o Congo; na América, o Amazonas e o Mississippi (GRATÃO, 2008).

$\mathrm{Na}$ água também constatamos as dinâmicas de poder exercidas em uma sociedade. A biopolítica (FOUCAULT, 2007) como forma de poder sobre a vida se expressa como dominação da água nas hidropolíticas (WOLF, 2007) por meio da legislação que instauramos, da série de técnicas que utilizamos, do tipo de distribuição, organização e planificação dos governos e da definição de privilégios e direitos. Inclusive, a privatização da água, a crescente apropriação legal e ilegal dos ecossistemas ricos em água, o crescimento do negócio da água de garrafa e o desprestígio da gestão pública da água, não são coisas que acontecem de graça, todas elas trazem relações de poder implícitas.

Estas hidropolíticas, jogos de poder em torno da água, são evidentes em casos como o negócio de água de garrafa que surge na Europa no século XVIII de um modo mais artesanal, relacionada às farmácias e a suas propriedades terapêuticas para, no século XX, crescer de forma muito rápida, ocupando supermercados, convertendo-se em umas das atividades econômicas mais importantes (VILAR-RODRÍGUEZ; LINDOSOTATO, 2014); ou as recentes políticas que procuram privatizar o fornecimento de água, sendo uma das mais conhecidas "A guerra da água" na Bolívia, ou a proibição de recolecção de água da chuva nos estados de Utah e Colorado, nos Estados Unidos. 
Por trás destas formas de poder, existem estruturas de pensamentos que estão ocultas na cultura, na sociedade, em toda a planificação e organização da água em nosso habitar. Assim, como aponta Ángel-Maya (1996) e Noguera (2004), para confrontar esta crise precisamos transformar todo o tecido de símbolos de nossa cultura, pois ao desconhecermos os tipos de pensamentos e os valores implícitos neles, desconhecemos de onde procedem nossas decisões e atos. Temos sido ingênuos ao acreditar que esta racionalidade científica moderna capitalista não possui mitos. Não apenas os possui como estão muito mais arraigados do que supomos. Em relação à água, alguns destes mitos são: discursos de escassez da água, água de garrafa como símbolo de maior pureza e uma gestão privada da água como melhor que a gestão pública (PIÑEYRO, 2006; PORTO-GONÇALVES, 2006).

\section{Hidropoéticas no habitar urbano contemporâneo}

As hidropoéticas que vamos narrar são da região sudeste da cidade de Campinas, no estado de São Paulo/Brasil, perto do rio Piçarrão, onde se encontram os bairros: Vila São Bento, Jardim Miranda, Vila Manoel Ferreira e Jardim Santa Vitoria.

Por que eleger um lugar urbano, um conjunto de bairros consolidados, onde o pequeno rio se encontra canalizado, invisível e ausente na paisagem do habitar urbano? É justamente por este potencial de ausência que a potência da presença se impõe.

Primeiro, há uma importância histórica e simbólica da água para a cidade. Gratão (2008), por exemplo, destaca o importante papel que tem a água para os habitantes das cidades, sendo ambientes geográficos valorizados, revelando como muitos dos lugares que se tornam atraentes para as pessoas e permanecem em suas mais queridas lembranças têm a imagem da água neles. Não obstante, a crise da água desvela dramaticamente a dualidade emocional nas relações com ela. A dualidade de sentimentos topofílicos (TUAN, 2012) e topofóbicos (RELPH, 1979) frente aos lugares da água é mais marcada no urbano; por um lado, observamos que muitos dos lugares sonhados e idealizados pelas pessoas possuem água, por outro lado há um medo latente com as águas urbanas. A água que serve para fundar e manter nosso habitar, que traz sentimentos de afeto, admiração e apego, igualmente infunde sentimentos de medo, ódio e insegurança.

Este sentido de fundação, do lugar de nascimento e de salvaguarda da memória foi desvelado nas narrativas do lugar pesquisado a partir da imagem hidropoética Fundar um morar. O rio Piçarrão, o articulador dos bairros deste lugar, teve um papel importante na criação destes bairros e na chegada de seus primeiros moradores. Foi em suas proximidades que se criaram as ferrovias e rodovias, que logo permitiriam a entrada do comércio. Nas proximidades da rodovia Anhanguera, cujo trecho que alcança Campinas é inaugurado em 1948, e da avenida John Boyd Dunlop, construída em 1953 (SANTOS, 2002), se localizaram uma série de indústrias e vilas operárias; as quais, por 
serem geradoras de empregos, atraíram muitas pessoas à procura de possibilidades laborais e que, ao encontrá-las, decidiram morar ali.

Compreendendo o lugar como a primeira qualidade existencial (OLIVEIRA, 2012), centro de significação no qual se dão nossas experiências, podemos aventar que a fundação de um lugar funda a própria possibilidade de existir. No entanto, nem toda localidade tem significados ou é importante um existente, nem toda localidade é um lugar (GRATÃO, 2007).

Todo lugar é um espaço habitado, fazendo referência ao mundo vivido, base de nossa própria existência; nele constituímos e fundamos nosso habitar, pelo qual toda experiência é mediada por eles (MARANDOLA JR., 2014; BERNAL; MARANDOLA JR., 2014). Os lugares são construídos e nos constroem. Realmente não os ocupamos: somos eles. Assim, é impossível não ter um lugar (MARANDOLA JR., 2012). Esta concepção está inspirada diretamente na filosofia heideggeriana, segundo a qual não são os espaços que possibilitam os lugares, e sim, os próprios lugares que outorgam os espaços (HEIDEGGER, 2012b).

Os lugares não possuem um sentido único, mas sim podem ser pontos de encontro, coisas em comum, traços engendrados entre o individual e o coletivo. Não são territorialmente delimitados, generativos e regenerativos. São definidos, mas não determinados, e não são, eles passam (CASEY, 1996).

São as marcas entre a relação homem e terra, condição de possibilidade para o homem, onde se dão os laços com os outros e se constroem nossos processos de identidade, a partir dos quais forjarmos as comunidades e as sociedades. $\mathrm{O}$ homem vive o mundo, mas é na escala do lugar que os fenômenos da natureza simbólica e social são sentidos (BERNAL; MARANDOLA JR., 2014). Espaços de resistência, construídos na circunstancialidade, fazem parte de nosso cotidiano e são resultado das relações e das experiências que se tecem nas diferentes situações, fazendo com que sejam dinâmicos e superem os contextos históricos (MARANDOLA JR., 2012).

Se consideramos que todo lugar é um espaço habitado, ele leva implícito o verbo habitar, nele e com ele somos e, como bem sabemos, todo lugar para ser habitado precisa de água. Assim, o lugar só é possível pela água. Este caráter necessário da água para eles já foi expresso assim por Malpas (2006, p.1 - tradução livre):

A água é fundamental para o lugar, e, portanto, também para toda a vida e habitar do lugar. Além disso, a própria vida humana é essencialmente determinada por seu entrelaçamento em lugar e lugares, portanto é constituída, embora indiretamente, talvez, por 
meio da água e suas formas (PIÑEYRO, 2006, p.5 - tradução livre). 1

Uma potente segunda imagem hidropoética que nos ajuda a compreender a água no habitar urbano contemporâneo seria Rio próximo e distante ao mesmo tempo. Esta se refere ao sentido de proximidade e distância ontológica ou, dito de outra forma, da visibilidade-invisibilidade do rio.

De todas as imagens da água, a do rio foi a mais visível, no entanto, se observou uma distância. O Piçarrão como muitos rios na cidade encontra-se canalizado e em muitos pontos ocultos pelas ruas, rodovias e espaço construído. Sentidos que tradicionalmente são ligados ao rio têm mudado ou desaparecido, fazendo com que haja um maior anonimato do rio. $\mathrm{O}$ barulho da água batendo contra as rochas já não se escuta, a fauna e a flora que lhe davam contornos e vida são escassas e na paisagem o rio se desvela levemente na diferença de relevo, quase imperceptível pelo fluxo do trânsito dado pelo traçado e forma das ruas.

As distâncias entre o rio e as pessoas parecem maiores na atualidade, porque embora se encontrem na mesma localização, as experiências com ele mudaram. Muito do contato que se tinha se perdeu. A possibilidade de nadar e pescar já não existe. Inclusive, uma das moradoras relata como em sua infância, quando não haviam tantas casas, o rio parecia mais próximo.

A ambiguidade de sentimentos topofílicos e topofóbicos foi exposta pelos moradores. Para aqueles a quem o Piçarrão remete mais a sentimentos topofílicos, esta é uma das melhores razões para viver ali, pois desejam que melhorem suas condições. Inclusive, vários deles semearam e criaram lugares de recreação nas margens do rio por conta própria. Por outro lado, para quem pensa que o rio é mais um lugar topofóbico, este deve ser tampado totalmente, esquecido e escondido, pois é associado com a atual contaminação do rio, com insegurança e com inundações que haviam ocorrido muitos anos atrás.

Temos também a perspectiva de muitos dos planejadores urbanos que contribuem para difundir uma série de valores hidrofóbicos, sobretudo a partir do paradigma hidráulico-sanitarista que tem imperado por décadas tem satanizado os rios, considerando-os um perigo sanitário que deve ser eliminado (BARTALINI, 2009; REYNOSO apud SILVA-SÁNCHEZ; JACOBI, 2012). Na perspectiva da água no urbano, a partir de um enfoque capitalista, esta entra na cidade como mercadoria e sai como resíduo reciclável. A partir de uma larga tradição de desprezo à água e sobrevalorização do sistema viário (BARTALINI, 2009), foi dada prioridade às vias,

\footnotetext{
${ }^{1}$ Water is elemental to place, and so also to all life and dwelling in place. Moreover, human life is itself essentially determined through its entanglement in place and places, and so is constituted, if indirectly, perhaps, through water and its forms.
} 
ocultando com cimento e canais os rios nas cidades. $\mathrm{O}$ anonimato e o desaparecimento dos rios nas cidades tal como afirma Bartalini (2009), tem sido um fator comum em muitos núcleos urbanos. Um claro exemplo disto podemos observar na cidade de São Paulo (Brasil) quando, nas décadas de 1980 e 1990, com o programa "Canalização de córregos", se canalizaram mais de sessenta quilômetros de rios na cidade (SILVASÁNCHEZ; JACOBI, 2012).

As imagens da água associadas a uma topofobia têm crescido no urbano, sendo cada vez menos as relações afetivas prazerosas com a água na cidade o que reforça seu distanciamento e invisibilidade. Associando a imagem da água na cidade aos lugares topofóbicos, os mesmos habitantes que sonham com lugares com água (não apenas abastecimento, mas para lazer como a praia, cachoeiras ou lagoas), clamam agora por seu ocultamente na cidade, pois a pobreza, o roubo, a contaminação, as doenças e as pragas estão ocupando as imagens do que poderiam ser lugares topofílicos. Hoje são mais frequentes as demandas dos moradores para que se ocultem as águas dos rios que se encontram a céu aberto. Muitos consideram que a melhor intervenção seria a canalização, já que não confiam que o governo vá melhor a sua qualidade (SILVASÁNCHEZ; JACOBI, 2012). Existe também uma evidente tendência de estratificação socioespacial, unida à imagem dos bairros marginais e da urbanização precária que têm acrescentado aos imaginários da água urbana a figura de lugar topofóbico.

Cada vez são mais invisíveis os rios na cidade. Agora é por meio dos vestígios (BARTALINI, 2009; 2014) que são perceptíveis. As ruas absorveram os rios, é até difícil compreender que muitas das diferenças do relevo se devem às linhas mais aprofundadas por onde passa a água. Para Bartalini (2014), trata-se da negação da própria paisagem. Só em épocas extremas, de abundante água ou grandes secas, a água de chuva e rios voltam a tomar um papel destacado na cidade e perdem um pouco o anonimato. A argentina Nidia Piñeyro, a partir de outro enfoque, nos fala destas águas ocultas e do distanciamento no urbano frente à água:

Dificilmente uma pessoa que viva na cidade pode ligar espontaneamente o conceito da água ao do rio, da chuva, do orvalho ou da água subterrânea. A imagem mais próxima em sua concepção da água se parece a água da torneira ${ }^{2}$.

É indubitável este distanciamento que aponta Piñeyro com as fontes de água na cidade, mas não é verdade que os moradores da cidade não relacionam as fontes originárias da água à água da torneira que têm em suas casas e trabalho. De fato, embora predomine o contato com a água da torneira, ainda se mantém latente, inclusive, quase

\footnotetext{
${ }^{2}$ Difícilmente una persona que viva en la ciudad pueda ligar espontáneamente el concepto de agua al de río, lluvia, rocío o de agua subterránea. La imagen más cercana en su concepción del agua se parece a un grifo.
} 
de forma romântica, a imagem do rio, das chuvas, do lago, das águas subterrâneas. Não se pode negar que existe uma distância das fontes de água em nosso cotidiano e que isto gerou uma ruptura com elas, mas também não se pode afirmar tão drasticamente uma perda absoluta da percepção delas. No conto do escritor Ítalo Calvino, se desvela o desejo das pessoas que moram nas cidades em suturar este distanciamento com a água e a esperança de ter novamente o papel do sagrado perdido em nosso habitar:

Acabo de acordar, ainda sinto os olhos cheios de sono, mas estou perfeitamente consciente de que o gesto que faço para inaugurar meu dia é um ato decisivo e solene, que me põe em contato ao mesmo tempo com a cultura e a natureza, com milênios de civilização humana e com o trabalho das eras geológicas que moldaram o planeta... e sei que para que esse milagre se repita diariamente, uma série de condições complexas deve estar reunida, razão pela qual a abertura de uma torneira não pode ser um gesto distraído e automático, mas um gesto que exige concentração, participação interior (CALVINO, 2001, p. 200).

Uma terceira imagem hidropoética se refere aos Momentos vulneráveis. Estes são especialmente relevantes em nosso urbano latino-americano, com a história de uma urbanização de risco que constitui, ela mesma, contextos de intensa vulnerabilidade (KOWARICK, 2009; MARANDOLA JR., et. al., 2013; NUNES, 2015).

Ao ser o rio tão importante na constituição dos bairros e do lugar, ganha predominância sobre as outras formas da água, enquanto as outras manifestações da água, como a da torneira, de garrafa, ou subterrânea passam desapercebidas mais facilmente. São necessárias grandes rupturas na normalidade perceptiva e simbólica para que possam ser trazidas à consciência novamente. Estas rupturas se apresentam através de acontecimentos como inundações, contaminação da água, falta de abastecimento, etc.

Em nossa pesquisa, foi visível nas experiências dos moradores que a água para uso doméstico aparece com maior força no início da constituição dos bairros, quando ainda não tinham um sistema de abastecimento e deviam usar a de um caminhão-pipa que ia com uma frequência de um ou dois dias, normatizando os hábitos das pessoas. Os moradores deviam dedicar todos os dias algum tempo para fazer fila frente ao lugar onde chegava o caminhão-pipa e coletar um pouco de água, que deviam saber distribuir para que durasse até a próxima vinda do caminhão-pipa. Com as inundações, acontecia algo bastante interessante: eram ocasionadas pelas chuvas, mas eram percebidas no rio, que ficava como a imagem predominante na memória das pessoas.

A escassez da água, uma ausência material, marca um dos momentos vulneráveis, mas é pelo excesso, pela rapidez e pelo volume que a água deixa de ser rio e se torna inundação. Esta é outra dissociação que opera no habitar, tornando a água risco e perigo (HEWITT, 1983; 1997), expressão de desastre e medo (TUAN, 2005). 
O lugar que emerge neste habitar é um habitar em risco (MARANDOLA JR., 2014), de um ser-no-mundo que experiencia a vulnerabilidade como dimensão de sua própria existência, transmutando a água, que é vida, em morte. A própria crise de abastecimento, que retorna à realidade depois deste período de fundação, agora é configurada como crise hídrica por todo o estado de São Paulo (JACOBI; CIBIM; LEÃO, 2015; MARANDOLA JR., 2015).

A Chuva é também uma imagem hidropoética forte na experiência deste habitar urbano, manifesto em três sentidos principais: inundações, goteiras e exuberância. Na primeira manifestação, as grandes quantidades de chuva e a falta de uma boa planificação fizeram com que o rio inundasse, ocasionando perdas que foram maiores para as casas mais próximas. Neste caso, as experiências dos moradores estiveram mais presentes nos primeiros anos do bairro e antes da canalização do rio.

Na segunda manifestação das goteiras, aparece no começo dos bairros, já que a maioria dos moradores tinham uma condição de poucos recursos, seja pela condição de trabalhadores, seja pela condição de migrantes (muitos vindos do campo), que ocuparam as casas sem necessariamente estarem concluídas (sistemas de auto-construção), apresentando. muitas delas sérios problemas no teto. Uma das moradoras relatou que quando chovia muito forte parecia que havia mais água dentro do que fora da casa.

A terceira manifestação, de exuberância, se dava nos dias posteriores às chuvas intensas. $\mathrm{O}$ ambiente mudava notadamente, podiam-se sentir mudanças na humidade relativa do ar, uma frescura enchia a atmosfera, o rio mostrava maior vivacidade e podia chegar a aumentar seu caudal e se fazer mais barulhento.

Nas diferentes narrações do lugar expressas nas imagens hidropoéticas, a água se manifesta pelas fendas de acima ou de baixo, em suas escritas da terra como tecido material e simbólico. Os caminhos dançantes, ou seja, suas hidrografías-coreografías, são as escritas que se expressam como canto nas hidropoéticas, como maneiras de ser e estar da água, sabendo-nos, nós, humanos feitos de água (NOGUERA; BERNAL, 2015).

Estas hidropoéticas anunciam os espaços habitados, com elas procuramos a pletora de significados da água. São propostas poéticas e políticas ao evocarem a água em suas diversas maneiras de ser e nomear as múltiplas experiências referentes à água, as variadas formas de existir e de habitar. As hidropoéticas são narrativas conjuntas manifestas nas vivências, nos mitos, lendas, metáforas, imagens, paisagens e biografias das pessoas. São, como muitos saberes tradicionais, formas de romper com a visão de uma água objetivada e do sujeito dominador (BERNAL, 2015). São águas habitadas, vividas, experienciadas. Embora todo lugar se deve à água, nem toda água é um lugar. É, antes, a possibilidade dele:

A hidropoética emerge conjuntamente com o lugar como aquela dupla marca que se dá entre o homem e a terra. Este lugar é sendo na proximidade, no espaço de encontro com a terra e configura-se naquele espaço vivido onde surgem as afetividades, as 
experiências, onde fica a marca, o lugar é o caminho e ponte que possibilita o pertencimento à terra (BERNAL; MARANDOLA JR., 2014, p.166, tradução livre). ${ }^{3}$

Deste modo, as hidropoéticas nos oferecem as possibilidade de vivenciar as águas no mais profundo delas e de nós, de voltar a um encantamento que nos lembra a água que somos e o lugar dela em nosso habitar, coreografías da água na terra com o homem, fissuras que se dão através da água-lugar-experiência, que marcam esta água em e com nosso corpo, em nosso estar e em nosso ser, ou seja, em um habitar hídrico.

\section{A emergência hídrica nas ausências}

Encontramos nas narrações a partir das experiências dos moradores dos bairros estudados vários sentidos de grande profundidade simbólica. No primeiro, "Fundar o morar", se relatou como o habitar nesta região de Campinas/Brasil surgiu graças à água, como as oportunidades de viver, as possibilidades de obter um trabalho para criar e manter uma família e ter um lar foram e são possíveis pela água. No segundo sentido sobre "Rio próximo e distante", desvelou-se a imposição de um sentido do rio guiado por um aumento de sentimentos topofóbicos do rio no urbano, em seu ocultamento, cada vez mais distante e ausente, mais anônimo. Nos "Momentos vulneráveis", se ressaltou a invisibilidade de outras formas de água e sua fugaz aparição em momentos de ruptura, ligados mais a situações de risco, perigo e necessidade.

A respeito da chuva, a diversidade de sentidos topofílicos e topofóbicos mostra a ambiguidade presente nos múltiplos sentidos que pode ter a água.

Se é verdade que estes relatos hidropoéticos não nos permitem definir nem a água nem o lugar, ao narrá-los a partir das experiências, podemos compreender melhor aquilo que os constituem. A divergência de sentidos que se mostraram nas narrações hidropoéticas desvelaram as diferentes experiências do lugar para as pessoas. Estas hidropoéticas permitem compreender o lugar nascendo graças à agua.

As águas das experiências não possuem uma linha fixa nem facilmente delimitada, os sentidos não são únicos nem iguais para todos os moradores e, portanto, os sentires são diferentes entre as pessoas. As situações e vivências variam entre os habitantes e ainda assim é possível a experiência, a imagética e a constituição de lugares, sendo a água sumamente importante e necessária para estes.

${ }^{3}$ La hidropoética emerge conjuntamente con el lugar como aquella doble marca que se da entre el hombre y la tierra. Este lugar es siendo en la proximidad, en el espacio de encuentro con la tierra y configura en aquel espacio vivido donde surgen las afectividades, las experiencias, donde queda la huella, el lugar es el camino y puente que posibilita el pertenecimiento con la tierra. 
Na cidade, no urbano, a contradição de sentimentos e a distância da água se mostram articuladas. No entanto, nem tudo está perdido. Ainda ficam traços de possibilidades e a urgência clamada por seus habitantes para um morar mais poético. Estas águas urbanas, nos dirá Gratão (2008), também são sagradas, sua dessacralização é expressão do grau de insensibilidade ambiental e da separação do homem com a terra. A água nas cidades anuncia e denuncia a situação e o estado em que o urbano se encontra. O modelo de habitar urbano está em franco questionamento, reflexo da própria cidade e, se esta e nossos lares são sagrados, também o é a água a qual devem sua existência.

Buscar as hidropoéticas é uma forma de retornar à água sua complexidade e mostrar o alcance de seu papel existencial, permitindo-nos continuar criando espaços de resistência e de luta, onde outras maneiras de habitar, atuar e nos relacionar sejam possíveis. Inclusive nas ausências, a água emerge como presença; é necessário, para ouvi-la, estar atentos a sua manifestação constituinte e episódica de nosso habitar, até no urbano contemporâneo em crise. É preciso considerar mais a água em sua constituição ontológica, em seu sentido terrestre ligado à geograficidade e a um habitar poético.

As grafias da água nas cidades, em nosso habitar urbano, se escrevem em letras fluídas por meio do ciclo hidrológico, grafadas pela água chuva que escorrega pelas ruas de cimento, na canalização dos rios, nas goteiras das casas etc. Se inscrevem nos corpos, nos sentimentos, emoções, desejos e memórias das pessoas. Nossa existência se inscreve na água e se escreve com ela. Ao passo que a água em suas variadas formas esculpe lugares na ambiguidade das presenças e ausências que brotam com a experiência. Igualmente, esculpe as pessoas, suas experiências e os lugares que dão forma à água, marcando onde e como pode fluir.

É na experiência que se encarna a poética da água, na maneira própria de cada pessoa para sentir e viver a água. A poética da água, ou hidropoética, é dança simbiótica, que da mão do habitar flui na relação homem-terra estendida como relação homem-água. Esta relação homem-água, como um necessário desdobramento da relação homem-terra, nos revela como no fundo o habitar, nosso habitar, é hídrico, ou seja, como nossa própria forma de existência é hídrica.

\section{Referências}

ÁNGEL MAYA, A. El reto de la vida. Bogotá: Ecofondo, 1996.

ÁNGEL MAYA, A. El retorno de Ícaro. Bogotá: PNUD, PNUMA, IDEA ASOCARS, 2002.

ARENDT, H. La condición humana. Barcelona: Paidós Ibérica, 2005.

BACHELARD, G. A água e os sonhos: ensaio sobre a imaginação da matéria. Tradução de Antonio de Pádua Danesi. São Paulo: Martins Fontes, 1989. 
BARTALINI, V. Os córregos ocultos e a rede de espaços públicos urbanos. São Paulo: Arquitextos, v. 106, p. 1-15, 2009.

BARTALINI, V. Córregos em São Paulo: a ocultação do avesso. Geograficidade, v.4, n.1, p.30-37, 2014.

BERNAL, D; MARANDOLA JR., Eduardo. Hidropoética del habitar y vulnerabilidad: la potencia del lugar en el contexto de la crisis ambiental. WATERLAT-GOBACIT NETWORK WORKING PAPERS. Thematic Area Series - SATAD TA8 - Water-related Disasters . New Castle: v. 1, n. 1, 2014, p. 158-172.

BERNAL, D. A rosa do deserto: hidropoéticas do lugar no habitar urbano contemporâneo. 2015. Dissertação (Mestrado em Geografia)) - Instituto de Geociências, Universidade Estadual de Campinas, Campinas.

BRUNI, J. A água é a vida. São Paulo: Tiempo social, v.5, n.1-2, p. 53-65, 1994.

CALVINO, Í. Um general na biblioteca. Tradução de Rosa Freire D’Aguiar. São Paulo: Cia. das Letras, 2001.

CASEY, E. How to get from space to place in a fairly short stretch of time:

phenomenological prolegomena. In: FELD, S; BASSO, K. H. (Eds.) Senses of place. Santa Fe: School of American Research Press, 1996.

CASTELO, L. A Percepção em Análises Ambientais - o Projeto MAB/UNESCO em Porto Alegre. In: DEL RIO, V; OLIVEIRA, L. (Org). Percepção Ambiental-experiência brasileira. São Paulo: Studio Nobel, 1996. p.23-37.

DARDEL, E. O homem e a Terra: natureza da realidade geográfica. Tradução de Werther Holzer. São Paulo: Editora Perspectiva, 2011.

FOUCAULT, M. El nacimiento de la biopolítica: curso en el Cóllege de France. Buenos Aires: Fondo de Cultura Económica, 2007.

GRATÃO, L. H. (À) Luz da Imaginação! O Rio se revela na voz dos personagens do lugar ARAGUAIA! Caderno de Geografia, Belo Horizonte, v. 17, n. 28, p. 89-120, $1^{\circ}$ sem. 2007.

GRATÃO, L. H. O 'Olhar' A Cidade Pelos 'Olhos’ Das Águas. Geografia, Rio Claro, v. 33, n. 2, p. 199-216, mai.-ago. 2008.

HEIDEGGER, M. Construir, habitar, pensar. In: HEIDEGGER, M. Ensaios e conferencias. Tradução de Emmanuel Carneiro, Leão Gilvan Foge e Marcia Sá Cavalcante Schuback. 8 ed. Petrópolis: Vozes; Bragança Paulista: Editora Universitária São Francisco, 2012a.

HEIDEGGER, M. Ser e tempo. Tradução de Fausto Castilho. Campinas: Ed. Unicamp, 2012b.

HEWITT, K. Interpretations of calamity: from the viewpoint of human ecology. Winchester: Allen \& Unwin, 1983. 
HEWITT, K. Regions of risk: a geographical introduction to disasters. Essex: Addison Wesley Longman, 1997.

JACOBI, P; CIBIM, J; LEÃO, R. Crise hídrica na macrometrópole paulista e respostas da sociedade civil. Estudos Avançados, v. 29, n. 84, p.??-??, 2015.

KAHTOUNI, S. Cidade das águas. São Carlos: RiMa, 2004.

KOWARICK, L. Viver em risco: sobre a vulnerabilidade socioeconômica e civil. São Paulo: Ed. 34, 2009.

MALPAS, J. The forms of water: in the land and in the soul. Transforming cultures $e$ journal, v. 1, n. 2, jun. 2006. Disponível em http://epress.lib.uts.edu.au/journals/index.php/TfC/article/view/257. Acesso em: $15 \mathrm{dez}$. 2016.

MARANDOLA JR., E. Lugar enquanto circunstancialidade. In: MARANDOLA JR., E; HOLZER, W; OLIVEIRA, L. (Orgs.). Qual o espaço do lugar? Geografia, Epistemologia, Fenomenologia. São Paulo: Perspectiva, 2012. p. 227-247.

MARANDOLA JR., E. Habitar em risco: mobilidade e vulnerabilidade na experiência metropolitana. São Paulo: Blucher, 2014.

MARANDOLA JR., E. Vulnérabilité, adaptation et résilience: une approche expérimentale. In: BERDOULAY, V; SOUBEYRAN, O. (Dir.) Aménager pour s'adapter au changement climatique: quelle nature fabriquons-nous? Pau: PUPPA (Presses de l'Université de Pau et des Pays de l'Adour), 2015. p.97-115.

MARANDOLA JR., E; MARQUES, C; DE PAULA, Luiz T.; BRAGA, Letícia C. Crescimento urbano e áreas de risco no litoral norte de São Paulo. Revista Brasileira de Estudos de População, v. 30, p. 35-56, 2013.

MARTOS-NÚÑEZ, E; MARTOS-GARCÍA, A. Memorias e imaginarios del agua: nuevas corrientes y perspectivas. Agua y Territorio, España, n. 5, p. 121-132, ene.-jun. 2015.

NOGUERA, A. El reencantamiento del mundo: Ideas filosóficas para la construcción de un pensamiento ambiental contemporáneo. México: PNUMA /ORPALC Serie PAL • 11 Universidad Nacional de Colombia Sede Manizales, 2004.

NOGUERA, A; BERNAL, D. La naranja azul: el agua en la era planetaria. Manizales: Geograficidade, v. 5, n. 2, p.??-??, Inverno 2015.

NUNES, L. H. Urbanização e desastres naturais: abrangência América do Sul. São Paulo: Oficina de Textos, 2015.

OLIVEIRA, L. Qual é o espaço do lugar. In: MARANDOLA JR., E; HOLZER, W; OLIVEIRA, L. (Orgs.). Qual o espaço do lugar? São Paulo, Perspectiva, 2012.

PARDO, J. L. Sobre los espacios pintar escribir, pensar. Barcelona: Serbal, 1991. 
PIÑEYRO, N. Agua y semiótica. Revista Polis, Chile, n. 14, 2006.

PORTO-GONÇALVES, C. El agua no se niega a nadie: La necesidad de escuchar otras voces). Revista Polis, Chile, n. 14, 2006.

RELPH, E. As bases fenomenológicas da geografia. Geografia, v.4, n.7, 1-25, abril, 1979.

SANTOS, A. C. Campinas, das origens ao futuro: compra e venda da terra e água em um tombamento na primeira sesmaria da Freguesia de Nossa Senhora da Conceição das Campinas do Mato Grosso de Jundiaí (1732-1992). Campinas: Editora da Unicamp, 2002.

SILVA-SÁNCHEZ, S; JACOBI, P. Políticas de recuperação de rios urbanos na cidade de São Paulo possibilidades e desafios. R. B. Estudos Urbanos e Regionais, v. 14, n. 2, nov. 2012.

VILAR-RODRÍGUEZ, M; LINDOSO-TATO, E. La industria del agua embotellada en Europa, siglos XIX-XX. Agua y Territorio, España, n. 4, p.108-124, jul.-dic. 2014.

WOLF, A. Vulnerabilidad y resistencia. Hidropolíticas en aguas internacionales. Oregón: Programa de las Naciones Unidas para el Medio Ambiente (PNUMA), Universidad Estatal de Oregón, EE.UU, 2007.

TUAN, Y. Paisagens do medo. Tradução de Lívia de Oliveira. São Paulo: Edunesp, 2005.

TUAN, Y. Topofilia: um estudo da percepção, atitudes e valores do meio ambiente. Tradução Lívia de Oliveira. Londrina: Eduel, 2012.

Diana Alexandra Bernal Arias

Doutoranda em Geografia pela Universidade Estadual de Campinas (Unicamp). Mestra em Geografia pela Unicamp. Graduada em Engenharia Ambiental pela Universidad Nacional de Colombia.

Rua Pedro Zaccaria 1300, Cidade universitária, CEP: 13084-350 - Limeira, SP Brasil.

E-mail: dianabernal@ige.unicamp.br

Eduardo Marandola Junior

Professor Associado da Faculdade de Ciências Aplicadas (FCA) da Universidade Estadual de Campinas (Unicamp).

Rua Pedro Zaccaria 1300, Cidade universitária, CEP: 13084-350 - Limeira, SP Brasil.

E-mail: eduardo.marandola@fca.unicamp.br

Recebido para publicação em março de 2017

Aprovado para publicação em janeiro de 2018 